\title{
Approaching the complex spatialities of early childhood education and care systems from the position of the child
}

\section{Sabine Bollig}

Abstract: This paper proposes a way to understand what early care and education systems look like from the vantage point of the child. In other words, it aims to fuse a system perspective and a child perspective of early childhood education and care (ECEC) in a way that acknowledges children as active co-producers of ECEC landscapes. In developing this approach, I emphasize that children's individual education and care arrangements which combine certain ECEC settings and the family are to be understood as networks of relations. As such, these child, family and ECEC relations create particular spatialities and temporalities which in turn position children very differently within the field of early education and care. To conceptualize how this takes place in children's everyday activities, I refer to Schatzki's and Massey's relational thinking about practices, spaces, time and multiple identities with special emphasis on the spatial relations that are 'beyond' certain localities and (re)produced in the 'events of place'. How this helps to understand the ways in which ECEC systems look from the position of the child will get exemplified in regard to Luxembourg's complex 'double split system' of ECEC and its complex language terrain.

Keywords: care and education arrangements, ECEC systems, spatial approaches, children's perspectives.

\section{Introduction}

Recent years have shown multifaceted efforts of the Luxembourgian government to reorganize the complex national system of early childhood education and care (ECEC) in a more 'child-centred way'. These initiatives 
ranged from implementing new guidelines for non-formal education based on the idea of children's individual learning trajectories and their right to participate, to certain legislations which aimed on improving the quality of the very heterogeneous ECEC services and the cooperation between them (see Honig \& Bock, 2017). Starting from this new semantic of a child-centred policy rationale, this article raises the question of how those political ambitions might benefit from child-centred ECEC research approaches, which put children's perspectives and their unique contributions to ECEC services into the front. However, puzzling together how children participate in ECEC systems, including how they actively co-produce their provisions they participate in across different forms of ECEC and the family, seems to be a still open task in that field of research. This article aims to fuse a system perspective and a child perspective of ECEC by first exploring how spatial thinking might help to understand how the Luxembourgian field of ECEC and its complex language terrain look like from the child's participant's position.

\section{Exploring ECEC Systems from a Child-Centred View}

This article stems from the premise that even though we have witnessed a recent increase in child-centred studies related to early childhood institutions, the question of what welfare states' systems of early education and care look like from the position of the child has not really been addressed so far. There is indeed a growing field of research dedicated to children's perspectives in ECEC. Related studies ask, for instance, about children's viewpoints on 'good day care' (e.g., Clark, Kjorholt \& Moss, 2005), and how children as situated actors make sense of the social, ethnic and language composition of diverse ECEC services (e.g,. Seele, 2016) and actively reproduce the specific culture and precepts of ECEC facilities within their peer cultural routines (e.g., Corsaro, 2018). Exploring ECEC services from the child's perspective has thus become a central topic of studies located at the intersection of ECEC research and childhood studies; the latter representing the interdisciplinary field of research investigating the ever-changing societal formation of childhood as well as children's agentic reproduction and transformation of it within their lives as children (Qvortrup, Corsaro \& Honig 2010). This child-centred research points out very clearly that children are not just addressees but also powerful actors in the ECEC institutions they attend (Markström \& Halldén, 2009), making important contributions to them both individually and collectively. Hence, what most of these studies have in common is that they mostly locate children's participation and perspectives in ECEC on a very local level within respective facilities - or, to 
borrow Ward's (1978, cited in Ansell, 2009, p. 191) phrase, the studies construe children as "colonizers of small spaces". And this applies also for the fairly new research approaches which uses spatial thinking to investigate children's active participation in the ongoing reproduction of their spaces and places in ECEC (see Bollig \& Millei, 2018).

Research asking what ECEC systems look like from the position of the child can thus build upon this child-centred research, as it shares the ambition to start from the vantage point of children - but has also to expand its scope. And this is precisely because it not just asks about the small and contained spaces societies dedicate to young people. Instead, it seeks to explore systems of ECEC, or more precisely, the (trans)nationally and communally governed, historically shaped, geographically uneven and economically mixed landscapes of diverse yet interrelated ECEC services. To explore how these landscapes shape and are being shaped by children's activities, we have to take into account first that children experience those in heterogeneous ways. This heterogeneity is arising from children's diverse enrolment histories and their respective spatial and temporal and inter-relational positionings between certain ECEC services and the family (Gulløv, 2003; Kousholt, 2011). From the position of the child, the landscapes of ECEC comprises, thus, a multiplicity of different care and education arrangements.

Those care and education arrangements (or ECEC arrangements), are to be understood in the first instance to include the horizontal and vertical chains ${ }^{1}$ of different settings combined by parents in order to provide for their children's care and early education (e.g., Betz, 2013; Claessens \& Chen, 2013). The dynamic processes of setting up those ECEC arrangements are characterized by an interplay of families' different needs and resources, diverse regulations, particular local landscapes and organizational enrolment procedures - in other words, by the "dynamic relationship between accessibility and desirability" (Vandenbroeck et al., 2008, p. 245). In consequence, these ECEC arrangements differ significantly in terms of complexity (how many services are combined), stability (how often they change over time) and quality (what kinds of services are combined). Furthermore, they reflect familial and regional inequalities (e.g., Sylva et al., 2006).

The horizontal chain refers to the daily combinations of e.g. childminder, grandparents and preschool, whilst the vertical chain refers to the transitions between those over the life course. 
Nevertheless, those arrangements do not only represent different forms of participation in ECEC. Rather, as this article aims to show, they have to be understood as diverse networks which interrelate particular places (e.g. day care centres, childminders, preschools, homes, grandparents, etc.), people and activities to each other in specific ways. As relational networks they shape children's particular positions and experiences across and within certain ECEC and familial sites: within certain services, children might, for instance, have individual schedules of attendance resulting in completing different tasks as part of their daily arrivals and departures (Mohn \& Bollig, 2016). Individual schedules also have implications for finding playmates (de Groot Kim, 2010) and for the coordination of the children's needs and interests in accordance with the organizational scheduling of activities and people (Bollig, Honig \& Nienhaus, 2016). Across services and the family, children participate in very diverse relationships within among those places and peoples, for instance, in customer-like relations or community-based relationships between the families and childminders (O'Conell, 2010; Bollig, 2016) or the often more authoritarian relations between public day care/ preschools and families (e.g., Karila \& Alasuutari, 2012).

Furthermore, and given their central position within these networks, children are not just active members of these relationships but also have to deal with diverse localized cultures at various sites (e.g., Brooker, 2006). The home, the day care and the preschool are meaningful places, offering specific expectations, norms and emotional attachments as well as particular resources for place-related identities. This is the reason why children's days between family and ECEC result in children's "multiple identities" (e.g., Heedegard, 2010), which in turn inform their learning and socialization across these places in terms of "multiple becomings" (Hengst, 2018). From the position of the child, the field of ECEC can thus only be adequately understood with a view to the complex "positionalities" (Sheppard, 2002) that link people and places with one another in space and time. Consequently, those complex positionalities also raise attention to the resulting heterogeneity of and negotiations in ECEC places, because the different people are positioned differently and enact their own 'senses of place' (Massey, 2003).

In this article, I argue that child-centred research on ECEC should be expanded to those more complex time-spaces which shape and are being shaped by children's participation in ECEC systems. In particular I show that children's ECEC arrangements are very much the 'sites' which contextualize children's enacted positions in ECEC and their related multiple identities and agencies. For this end, I conceptualize those ECEC arrange- 
ments as complex, ever-shifting, practised time-space configurations which take place in children's participation in and across ECEC services, instead of being just an outside condition of children's everyday experiences.

\section{Processual Spaces and Places}

For exploring ECEC systems from such a child-centred perspective, I use practice theories which state that local practices can never be understood only from the localities in which they occur. Rather, they result from the complex interconnectedness with other practices in space and time, and they produce those same spatial and temporal relations at the same time as well. In particular, I draw on the work of social philosopher Ted Schatzki (2002, 2011) and geographer Doreen Massey (1994, 2005), who both reject the 'classic' concept of space as an Euclidian container for activities. Rather, both view space as a fundamental part of practices and, therefore, always in the process of being made and inseparably interwoven with time. Furthermore, both reject two purified ways of conceptualising spaces: first, that sees spaces as subdivided into reified, stabilized entities separated by hermetic boundaries (as in the scalar division of national systems/spaces and local practices/spaces of ECEC); and second, that sees spaces as pure flux without any persistence (Schatzki, 2011; Massey, 2005). Instead, they both locate the unceasing production of even very large and extended spaces in the bodily occurrence of widely interconnected practices which occur in particular localities and in their socio-material set-up. Hence, for Schatzki (2011), it is precisely those local bundles of practices and material arrangements ("practice-arrangements-bundles"), which allow for expansion in time and space. Likewise, Massey $(2003,2005)$ points to the powerful spatial relations which make up the positionality of people and places within the flows and mobilities which go through those localities. Based on this thinking about expanded spaces which occur in certain localities, Massey's (2003, 2005) concept of space/place is of particular interest, as it allows for the analysis of the complex socio-spatial relations which are produced in and across certain localities in relation to the production of children's multiple identities, or to their 'more than local' senses of place.

For Massey (2005), space is a product of interrelations, constituted through interactions "from the immensity of the global to the intimately tiny" (p. 9). Places, like children's bedrooms or day care centres, are instead distinguished by their material localization and discrete meaning. Whereas productions of space lead us to experience that persons and objects are interrelated, places, thus, emerge out of the fixing of particular meanings 
of space. This is also why places permit a 'sense of place', that is, the evershifting experience of place-specific identity which is created via participation in practices connected with said locale. Hence, the qualities of places cannot be understood merely within their fixed, local contexts, as they include manifold relations that stretch 'beyond'. Nor can place ever be considered complete. Massey (2005) views places as a "constellation of processes rather than a thing" (p. 125), consequently, we have to think about places in terms of the "event of place" (p. 141). Or, as Massey (2003) writes: "[I]f the spatial is thought of in the context of space-time and as formed out of social relations at all scales, then one view of a place is a particular articulation of those relations, a particular moment in those networks of social relations and understandings" (p. 5). This importantly includes "relations which stretch beyond" (p. 5) and this occurs "precisely (in part) through the specificity of the mix of links and interconnections to that 'beyond'. Places in this way are open and porous" (p. 5).

To understand, how this mix of links and interconnections comes at work in the event of place, Massey $(2003,2005)$ uses the concept of "trajectories" or "stories-so-far". These are the multiple socio-material and discursive lines of becoming that serve as both the practical resources and the paths for the practical generation of meaning and its effects. As resources, they materially, socially and symbolically contribute to the "event of place", and as paths they relate it to other instances. Those paths could be strongly or weakly bound to the materializations of the place, have a longer or shorter 'history' of their own, and could create different far-reaching interrelations (including both small and extended spaces). However, they always have an effect on the unavoidable negotiation of the here-and-now and on the necessity of coming to terms with others. Thus they are inextricably woven into the practices of giving meaning to places, or better, place-making.

Importantly, given Massey's and Schatzki's flat notion of the social in which all scales are (potentially) present in all practices at all times, places like day care or preschool are made up by a multiplicity of trajectories. Those particular articulations of relations unfold within multiple stories-so-far, "crosscutting, intersecting, aligning with one another, or existing in relations of paradox or antagonism" (Massey, 2005, p. 3). Space is then exactly this "simultaneity of stories-so-far" (p. 24) and, consequently, places are made up by a "throwntogetherness" (p. 150) of multiple, simultaneously present spatial relations. For the diverse people attached to those place this multiplictiy results, consequently, in the experience of heterogeneity and negotiation - or to say, those multiple trajectories are also part of the politics of place. 
In the following, I sound out the potential of this spatial thinking for investigating ECEC systems from the position of the child. I use Schatzki's concept of the interconnectedness of practices and Massey's concept of the multiple trajectories in an event of place to show how children participate in the everyday production of their care and education arrangements and its respective temporality and spatiality. I base this on an ethnographic case study conducted within the complex Luxembourgian ECEC system and its related complex language terrain.

\section{The Luxembourgian Context and its Doubly Split System of ECEC}

Despite the relatively early establishment of preschools in 1963, Luxembourg never paid much attention to public extra-familial childcare until the end of the last century. The last twenty years, however, have brought an enormous increase of day-care facilities with very flexible structures, and ever since the implementation of childcare vouchers in 2009, a mixed economy of childcare has proliferated (Honig \& Bock, 2017). All of this has contributed to Luxembourgian ECEC's complex structure, which I call a doubly split system.

Split systems of ECEC are understood as those systems which - while addressing the same age group - differentiate according to institutions' designated function, whether education or care (see OECD, 2015). This is the case in Luxembourg, with its historically rooted distinction between day care institutions (the crèche for children age 0-4 and the maison relais, foyer de jour for those age 4-12) and institutions for state-administered early childhood education (éducation précoce at age three $\&$ préscolaire at age four). In recent years, there have been enormous governmental efforts to reorganize the split system into a more integrated one, for instance, both came under the responsibility of a single government ministry in 2013. Nevertheless, there are still two sectors of ECEC services for children under school age which are separated from each spatially (in other buildings, areas, and districts), programmatically (different curricula and guidelines) and also administratively (different staff, funding and regulations) (see Honig $\&$ Bock, 2017).

Compulsory preschool starts at age of four, but for a year before that children can attend the optional education précoce. This kind of pre-pre-school was implemented in 1998, mainly as an educational offering to compensate 
for migrant children's lack of knowledge of Luxembourgish. However, over time, it has become an infrastructural service which is used by all kinds of families. As a result, éducation précoce is popular, even though it operates only part-time (mornings from 8:30-12:00 from Monday to Friday and afternoons from 2:00-4:00 pm on Mondays, Wednesdays and Fridays) and does not offer care before, between or after these times. A lot of working parents thus end up in combining several care and education settings into what are known as "multiple childcare arrangements" (Claessens \& Chen, 2013). There is a lack of statistical data on these types of arrangements, but it is known that more than half of the 32,000 children below age four attend childcare services (and those who attend the services of the approximately 500 registered childminders are not yet included in that number) and $71 \%$ of the three-year-olds are enrolled in éducation précoce. Thus, it is quite common for children to attend both day care and pre-preschool on a daily basis.

Moreover, there is an additional split in Luxembourgian ECEC according to the subfield of day care. On the one hand, there is a commercial sector of day care providers operating on a quasi-market. These include regulated childminders and centres run by for-profit providers. On the other hand, there are state-funded day care centres run by non-profit providers and the municipalities. All services accept the childcare vouchers and have to follow the guidelines of non-formal education. Hence, the state-funded centres - or 'conventionalized' centres as they are called - receive extra money from the state based on a contractual agreement binding them to higher standards of quality. The lower quality standards that apply the commercial sector manifest above all in staff members' language competencies with regard to Luxembourg's historically-rooted trilingual culture, in which Luxembourgish, German and French all serve as official languages. Commercial day care centres are only required to provide all three languages across the whole of their staff, whilst childminders must be able to communicate at least in one of the three official languages. By contrast, in state-funded centres, all staff members have to be at least bilingual (Luxembourgish plus German or French), a requirement related to the government's promotion of Luxembourgish as the 'official language of ECEC' (Seele, 2016). ${ }^{2}$

These quality regulations result in Luxembourgish being the predominant language in state-funded ('conventionalized') centres and French predomi-

2 This 'Luxembourgish-only' approach in state-funded day care transforms at time as the government released a new 'plurilingual education scheme' in 2017, which is though still based on Luxemburgish and French. 
nating in the commercial sector. When it comes to childminders, Portuguese is commonly spoken as well. As more than two-thirds of the places for children under the age of four are provided within the commercial sector, French and Portuguese are thus very likely be the 'unofficial languages' of day care in early childhood. This is especially the case in the capital and in the south of Luxembourg near the French and Belgian border, which is where lots of French and Portuguese speaking people live, where the most commercial day care providers operate, and where a large proportion of French-speaking staff members commute across national borders on a daily basis (Honig \& Bock, 2017). ${ }^{3}$

Consequently, the expression 'doubly split system' draws attention to the fact that Luxembourg's ECEC system is criss-crossed by multiple borders - organizational, administrative, programmatic and linguistic - which also create various borderlines and border zones in relation to the family. One of the conditions of this diversity of relationships with families is the highly multicultural and multilingual nature of Luxembourgian society, which has the highest proportion of migrants in all of Europe. In 2017, only 53\% of residents possessed Luxembourgian citizenship.

The diversity of Luxembourgian society in relation to the country's highly complex ECEC system was the starting point of the research project CHILD - Children in the Luxembourgian Day Care System. Its original hypothesis was that these multifaceted systems, borders and relationships are specifically reproduced and transformed not only in the socio-genesis of individual children's ECEC arrangements but also in the daily multi-sited enactment of those arrangements, resulting in a "diversity of day care childhoods" (Bollig, Honig, \& Nienhaus, 2016).

\section{The Luxembourgian CHILD Study: Rationale, Design and Methods}

The CHILD- project investigated the socio-genesis and daily practice of young children's education and care arrangements via 13 contrasting case studies. Analytically speaking, these ECEC arrangements were determined to be those networked practice-bundles (Schatzki, 2002) in which ECECpolicies, parents' beliefs and decisions, local landscapes of provision, and

$362 \%$ of the staff in all day care centers have a Luxembourgian passport, around $50 \%$ of staff members in for-profit care are speaking Luxembourgish and/or German and about $79 \%$ are residents, the others commute to work from France, Belgium and Germany (Honig \& Bock, 2017). 
practical organizational cultures collude with the day-to-day practices which integrate children in specific ways as 'day care children'. The analytical focus was thus set on trailing "the thick texture of interconnections" (Nicolini, 2009, p. 5) which make up the children's particular ECEC arrangements.

Within each of these case studies a multi-sited ethnography was conducted, including interviews with parents and professionals/providers and the gathering of additional data on the local landscapes of ECEC in which they participated (Bollig, 2015). Most importantly, the study was based on participant observations of the children's daily encounters in and between ECEC services (and in some cases also within the family). The cyclic periods of fieldwork and analysis ranged from three to 21 months, conducted by five researchers, each of whom spoke the languages of the ECEC arrangements they studied (Luxembourgish, French, German, and Portuguese). One of these researchers conducted a camera-ethnography with a particular focus on children's daily transitions (Mohn \& Bollig, 2016). The analysis proceeded according to a grounded theory approach, which included the analytical strategies of 'zooming in' and 'zooming out' with regard to the particular practices observed (Nicolini, 2009). 'Zooming in' asks about the socio-material and performative organisation of practices, understood as nexuses of bodily doings and sayings (Schatzki, 2002), in which children participate (such as getting into play, negotiating rules or performing pick-up routines). 'Zooming out' focuses on these practices' intersections in time and space (such as with parents' decision making processes, organizational cultures, and so on). Masseys $(2003,2005)$ approach was applied in both analytical strategies, by asking for how the trajectories which make up the event of place feed into local practices and at interconnects it with spaces 'beyond'. This all led to the mapping of key themes for each case study, resulting in eight detailed ethnographic portraits of distinct ECEC arrangements, including the interconnected familial, regional and organisational socio-genesis and daily practice of each (Bollig, Honig $\&$ Nienhaus 2016).

\section{Performing ECEC Systems through Language - A Case Study of the Complex Spatialities of ECEC Arrangements in the Event of Place}

In the following, I demonstrate how Massey's space/place-approach and Schatzki's concept of interconnectedness have informed our analysis. To do this, I examine parts of Kim's ECEC arrangement. ${ }^{4} \mathrm{Kim}$ is a boy of Asian background who was three-and-a-half years old at the time of the study and

$4 \quad$ All names and places have been pseudonymized. 

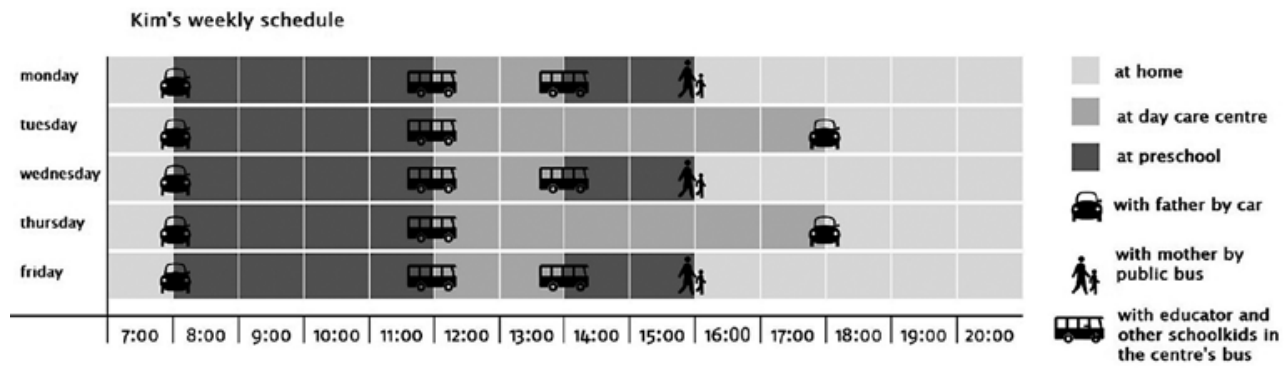

Figure 1: Kim's weekly schedule

lived in southern Luxembourg with his parents, both employed full-time. As the figure shows, Kim attended both the pre-preschool (éducation précoce) in his neighbourhood and the 'schoolkids group' (foyer de jour) in a larger day care centre in a neighbouring town on a daily basis.

Kim's ECEC arrangement is special, as it is characterized by the diversity of linguistic contexts he 'crosses' on any given day, and it is not only different languages but also different language regimes that play a role in his daily commute between his family, the preschool and day care centre. At home Kim speaks his Asian ${ }^{5}$ mother tongue with his parents and also a bit Italian, as the family used to live in Italy prior to their recently completed move to Luxembourg.

To explain the spatiality of Kim's ECEC arrangement, I start with his participation in a linguistic place-making during an everyday scene at the centre with a girl named Carla. In my analysis, I detail four trajectories which appear to be "cross-cutting, intersecting, aligning with one-another" (Massey, 2005, p. 3) in the respective place-makings. The analysis is thus structured by three questions. First, which place-makings are effective; second, which spaces 'beyond' the setting are actualized by those articulations of place; and third, which spaces are produced as a result. Although these 'stories-so-far'/trajectories are presented in succession, they should be understood as simultaneous and co-entangled.

One after on the playground of Kim's day care centre

In the after-school area of the expansive outdoor premises, the children - having played several games of tag - are now either playing alone or

5 Kim's parents asked explicitly for not specifying his nationality and mother tongue in detail. 
with each other in small groups. Carla rocks her upper body back and forth on a swing while Kim sits on the lawn, collecting small stones from the grass. After a while Kim runs over to Carla and as he approaches he shows her the stones in his hand. "Kuck, Carla" ("Look, Carla"), he calls to her in Luxembourgish, but at first she does not seem interested. "Nao" ("No"), she responds slowly in Portuguese. Kim stretches out his hand in front of her face: "Kuck elo, steeen" ("Look here, stones"). Now she smiles and replies, "Nao, suen", using the Luxembourgish term for "money". At this moment, François, the beloved main caregiver of the schoolkids' group, enters the playground. Several of the children run over to him, cheerfully shouting "François! François!" and trying to get his attention by explaining something to him in French. Kim, who has followed the group, tries to steer François' attention to his stones. "Kuck", he says, while sticking out his hand. Then he adds in French: " $J$ 'ai, ... j'ai ..." ("I have ... I have ...") but François is too tightly encircled by the bigger children to notice him. Carla, who joins Kim in the second row of children around François, takes the stones from Kim's open hand and suggests "mei" ("more") in Luxembourgish. She whispers something in his ear and marches away with the stones, causing Kim to follow her to a corner of the wooden castle. They spend the next 15 minutes occupied with picking small stones out of the grass and arranging them on a wooden board. They use body language to comment on and steer their 'work', and also engage in brief conversations using lowered voices whilst in close bodily proximity. All around them, the other children yell loudly, engaged in a movement game initiated by François. Later François allows Kim and Carla to join the younger children in the day care group in their separate upper play area. After a while, the two get into a conflict over who should hold my fieldnote book. Carla builds up an alliance with another Portuguese-speaking girl, who joins her in singing a song in Portuguese very loudly in Kim's face. "Dat ass net scheng" ("That's not nice"), Kim complains in Luxembourgish, twice, in a soft but serious tone. This appears to cause Carla to include him again. She holds out the fieldnote book, points to the birds on its cover, and calls out to him the Luxembourgish word for birds: "Vugelche". Kim repeats this and then they look at the book together.

The day care centre as s place of negotiating shared language use

The first trajectory to be highlighted here is children's practice of negotiating play and belonging (Stratigos, Bradley $\&$ Sumsion, 2014) via the use of language. Like many daily occurrences at the day care centre, this situ- 
ation is highly multi- and translingual and characterized by more or less explicit negotiations over the specific use of languages (Seele, 2016). The centre's 'schoolkids' group is an especially complex linguistic environment, given that most of the children in it are between six and 12 years of age and thus already speak or are learning French, German and Luxembourgish in school and/or at home. The children constantly jumble the languages in ways befitting their different family languages and personal linguistic preferences. The caregiver, François, however, speaks almost exclusively French as he has no command of other languages. Kim, for his part, uses Luxembourgish and French in order to negotiate his 'place' in the given situation. Both are relatively new languages for him, as he only just moved to Luxembourg at the beginning of the school term. Things are different for his interaction partner Carla, who also does not speak any of the three official languages of Luxembourg at home, but instead speaks Portuguese. Nevertheless, she can use her family language in the centre often enough since there is a high percentage of Portuguese-speaking families in this region and, consequently, a lot of Portuguese-speaking children (and educators too) at the day care centre. Thus, she can fall back on Portuguese as a 'regional ECEC language'.

In order to draw Carla's attention to his game and to continue playing with her, Kim uses Luxembourgish. Later he also makes use of Luxembourgish to express his disappointment over the two girls excluding him by language. Hence, his complaint and Carla's conciliatory reaction to it may be understood as the successful defence of their shared language of play in that situation. This actualizes in a particular way the routines of both children in the centre, where they, as the youngest members of the 'schoolkids' group, form a relatively stable pair who - unlike the older children - speak almost exclusively Luxembourgish with each other. This is why Kim's insisting on this routine also actualizes their shared experience of learning Luxembourgish in the pre-preschool class, and, thus, extends their shared space at the centre with that of the pre-preschool between which they commute. There are also other situations where their shared attendance of both institutions gets actualized, such as when they reference what happened in preschool in the morning, songs they learned there, or communicate their excitement about finding the same objects in both day care and preschool, including books and toys, as well as myself as a sort of 'strange' adult who accompanies them through their days. ${ }^{6}$ In all the situations within the centre, both

6 Such ECEC arrangements are very much a domain of children, which is what made me seem very strange as an adult present in all locations. 
children create a time-space of social relations which position them very much as pre-preschool children within the day care centre. Hence, this situation also highlights the fragile and challenging politics of place in which both children participate, as they share some equal positionings in the highly multilingual centre, but can also rely on different sources to exercise lingual power' in according to the language possibilities found there.

\section{The day care centre and pre-preschool as places of contested} language regimes

Hence, this positioning as pre-schoolers in day care is not only actualized by the negotiation of language use within and beyond the centre, but also in relation to the different language regimes Kim and Carla experience in their daily commuting.

In the éducation précoce that both children attend each day, the language situation is also decidedly multilingual, with many different family languages represented there. In the classroom itself, however, Luxembourgish is the only language the educators permit, applying also to recreation time in the school-yard. This restriction to one legitimate school language is intended by the teachers ${ }^{7}$ to encourage the acquisition of Luxembourgish and is justified by the perceived pre-preschool regulations (which in fact are very vague when it comes to language use) and to the classes' spatial positioning in school buildings. In order to 'deliver' to their colleagues schoolchildren who are 'ready for school', in terms of their command of Luxembourgish, the teachers mostly prohibit the use of other languages. The children contribute with their own 'linguistic policies' to this classification of legitimate and illegitimate languages. They do so by peer-culturally differentiating between 'loud' and 'quiet' languages. Kim, for instance, often plays with a group of boys who tend to speak French with each other and who do so very quietly to avoid attention. Carla, by contrast, often whispers with other girls in Portuguese. In general, one can hear children softly speaking 'forbidden languages' with one another throughout the day, thereby creating protected territories of play beside the demanding organizational language regime.

In the centre's schoolkids group, however, there are no language limitations, at least no programmatic ones. French is dominant there - especially

\footnotetext{
7 In the éducation précoce there is always a team comprised of a trained primary teacher and an educator (both called "Joffern"): the first is more oriented toward 'teaching', the second toward 'caring'.
} 
when the care worker François is present - only because he (like most of his colleagues) has limited competency in other languages. Consequently, there is also differentiation between language use with the educator and with the other children. However, as other languages are permitted at all times, the group's activities are correspondingly lively and multilingual, with choice of language predominantly based on comprehension and catering pragmatically to language competence (or to the desire to exclude by means of language as seen in the situation above). This 'laissez faire' language approach interconnects with ECEC regulations, which permit the employment of non-bilingual caregivers in commercial childcare centres. This results in a kind of reverse generational order within the centre, in which the older kids represent the multilingualism of Luxembourgian society and schools, whilst François, a French commuter, represents the less competent 'outsider' position. Kim and Carla, however, are positioned differently in relation to François, being the youngest there and not very good at French. These different organizational language regimes that come together in Kim's ECEC arrangement, thus, are connected to and create diverse spatial relations 'beyond' the particular locations, that is, the spatial relations of regional and transnational linguistic landscapes, the state and the nation (the latter apparent in terms of the recent importance accorded to Luxembourgish as the language of cohesion in an increasingly multicultural society).

Kim and Carla do participate in those language regimes in each setting, but they also create another kind of delimited language space in their daily experiences across those institutions. They do so in both settings by speaking very often to one another with voices lowered, as in the scene described above whilst playing with the stones. This type of play accompanied by speech in hushed tones is a very common feature of Kim's and Carla's peercultural place-makings in both institutions, although it produces particular effects. Whereas the children in the centre carve out protected territories of play by using lowered voices as a kind of escape from the group's loud and lively multilingual day-to-day activity, such protected territories are distinguished in pre-preschool by the children's resistant use of familial languages serving as a shelter from the demands of having to speak Luxembourgish properly. Therefore, Kim and Carla use precisely this kind of mobile practice to reproduce each of the different language regimes on site, and therefore, as a proper solution in both the highly policed spaces of language use in prepreschool and the challenging and excluding ones in the day care. Hence, these trajectories of negotiating and sheltering shared language use are interconnected with the different organizational practice-bundles beyond day care. They also cross-cut, intersect and align with the adults' trajectories 
apparent in that scene, one of those being the pragmatically-oriented practice of grouping in the day care centre itself.

The day care centre as place of ambitions towards, linguistic quality“ in for-profit childcare

In the scene above, Kim and Carla both commute within the centre as well, as later in the afternoon they move to one of the centre's toddler groups (crèche). The day care staff report that, given his age, Kim would be a better fit in that centre's crèche group, which is oriented toward children aged two to four. However, because Kim gets picked up from and brought back with the other schoolkids on a daily basis, he is, organizationally speaking, a member of the schoolkids group even though this group is oriented to older children (ages four to 12) in line with the start of compulsory schooling at age four. Given that most of the children currently in this group are over the age of six, Kim and Carla are the youngest, which often means that they are not included in the older children's collective games (as the scene above demonstrates). So in order to better suit Kim's and Carla's anticipated agespecific needs and their linguistic abilities, the day care staff often encourage them to join one of the crèche groups in the same centre.

For the centre's staff, this practice stems from their ambition to provide every child the most nurturing environment, although this often means to compromise between the children's perceived needs, staff members' availability and language competencies, and other organizational structures. One of these organizational structures - the age-related grouping according to the official school ages - is very much related to the mixed economy of ECEC, where caring for children outside of school hours and the provision of bus transfers between schools and day care has become one of the main 'unique selling points' of for-profit services in Luxembourg. This is the same for this day care centre, although this 'relation beyond' to the regional ECEC market regularly causes troubles to the staff in piecing together children, staff and rooms in the most 'caring' terms. Ironically, the staff's ambition towards higher and individualized quality, evidenced by occasionally allowing Kim to join the more Luxembourgish toddler group, positions Kim as a commuter between school and day care and within the centre. This in turn requires further linguistic negotiations of shared games and belonging, as in the example of the 'Portuguese-speaking alliance' in the scene described above. Therefore, this flexible placement within the centre shows very well how certain trajectories co-exist in such place-makings and are interconnected with diverse spaces 'beyond' the centre. 
The day care centre and the pre-preschool as complementary lingual places of care and education

Concerns about these complex linguistic demands in the field of Luxembourgian ECEC were also central to Kim's parents' initial navigation of his ECEC arrangement. Given that the family had just moved to Luxembourg, their search strategy seized upon Luxembourg's split ECEC system as a split between a 'language of education' and a 'language of care'. To enable Kim to make a smooth transition into compulsory preschool at age four, his parents purposefully selected the pre-preschool so that he could learn Luxembourgish beforehand. At the same time, they selected a day care centre in which their son would have an opportunity to speak Italian, which ties in with his prior day care experience in Italy and, thus, provide a language of care. (As his mother noted: "We wanted to choose in some way, for the first thing, who can speak Italian?") Thus they adopted Italian, which for him had once been a foreign language, into a kind of 'day care-mother tongue' within the new linguistic environment. Kim's day care centre seemed at first to enable this, because the director spoke some Italian and several children were from Italian-speaking families there. Hence, in their initial configuration of his ECEC arrangement, Kim's parents stretched across a transnational space connecting the national and regional language regimes with Kim's international language biography, thereby establishing the day care centre as a place of linguistic care and the preschool as a place of linguistic assimilation to new circumstances. In hindsight, his parents saw the preschool as the more 'providing' environment, having concluded from Kim's accounts that he liked being positioned just like the other children within the preschool's language regime. Since none of the children spoke the official school language at home, all were positioned as learners of Luxembourgish. As a result, in Kim's view, he did not stick out as a 'inguistically different child' there, as he sometimes felt he did in the day care centre (according to his parents' reports). This is also related to his identity as an ambitious learner who loves the 'schoolishness' of the pre-preschool. Thus, we can see how a processual place-making occurs in conjunction with the continual process of reflecting upon Kim's ECEC arrangement within the family. In this place-making, the relational meaning of day care and pre-preschool changes very much from a complementary relationship into a ranking, in which day care is now seen as providing 'less'. In the familial practices of making ECEC their place, the spatio-linguistic character of Luxembourgian ECEC is therefore reproduced in particular ways along Kim's migration history and also towards a reflexive positioning of the boy within the family's ongoing navigation of his ECEC arrangement. 


\section{The language related temporal-spatiality of Kim's ECEC arrangement}

Given how Kim's ECEC arrangement is actualized and produced within the place-makings analysed, we see that the daily creation of the arrangement's interrelated places (here: preschool and day care centre) establishes unique relational orders between persons and things, weaving together bodily proximity, and group-related, organizational, regional, national and transnational productions of space. As a result, all of these work together produce the ever-shifting temporalities and spatialities of Kim's education and care arrangement. Applying Massey's (2005) perspective on the throwntogetherness of multiple trajectories within the event of place, thus, renders visible the interconnected productions of space in and between the family, day care centre and pre-preschool. At the same time, it also illuminates how Kim practices his 'multiple identities' in these place-makings: as a pre-preschooler positioned between organizational and peer culture who differentiates between languages of achievement and resistance, or as ambiguouslypositioned day care child who negotiates vernacular speech vis-à-vis local ECEC languages and market-related organizational grouping practices; and yet again as a commuter between several languages - a linguistically somewhat different child' - who sits between the respective language regimes and the transitions between them.

The short example offered here thus unfolds the multiplicity of trajectories in Kim's daily place-makings, and also emphasises how those specifically intersect and position Kim in the respective ECEC settings and en route between them. His ECEC arrangement, therefore, creates its own complex fabric, which in turn shapes his positioning in the field of Luxembourgian ECEC and his own contributions to the daily process of its creation. Consequently, the double split of Luxembourg's ECEC system is reproduced by the everyday accomplishment of Kim's ECEC arrangement in a specific way: as the linguistic relationship between commercial and state-sector ECEC, regional ECEC and linguistic landscapes, and organizational language cultures - as well as the interconnected places in-between.

\section{Discussion}

In this article, first, I argued that if we ask how ECEC systems look from the position of the child, we first have to acknowledge that such systems manifest in (trans-)national and communally governed, historically shaped, geographically uneven and economically mixed landscapes of ECEC, in which families form complex interrelationships with distinct 
ECEC services. Second, I asserted that those landscapes are not stable entities, but occur and become actualized in multiple diverse networks - the ECEC arrangements of children - which interrelate particular places (e.g. day care centres, childminders, preschools, children's homes, grandparents' homes), people and activities, to each other in specific ways. I argued in particular that it is promising to research those ECEC arrangements by means of the application of spatial theories, which make visible the processual, positional and multiple constitution of these ECEC arrangements along interconnected practices that stretch in manifold ways 'beyond' the localities in which they take place. Massey's and Schatzki's concepts have been especially fruitful, as they both draw upon a flat concept of the social which renders visible children's position within ECEC, based on phenomena which are simultaneously multiple and positionally concrete, fluid and structured, standardized and individualized. Massey's approach in particular offers analytical resources to trace the temporal and spatial relations that come into play in the everyday enactment of particular ECEC arrangements and the multiple and shifting identities which are produced and negotiated as a result.

However, what lessons can we draw for child-centred research in general from such a complex study of the heterogeneous Luxembourgian system of ECEC and its complex language terrain? To address this question, I highlight very quickly some conclusions related to the advancement of childcentred approaches in ECEC research.

My first point is that child-centred thinking can do more for ECEC research then just focusing on daily encounters within the respective ECEC facilities. Thinking of ECEC places as 'open and porous' and understanding space as a 'sphere of multiplicity' (Massey, 2003) help us to understand that children not just a homogeneous group 'stuck within' their ECEC facilities and their neighbourhoods, but they are also the producers of heterogeneity and diversity within and across these sites. For this reason, I propose an expansion of the notion of children's perspectives to include the more spatial term of children's position, as positionality entails how certain entities are "positioned with respect to one another in space/time" (Sheppard 2002 , p. 318). Moreover, this view attends to the complex interrelations that contribute to the constitution of children's positions in certain ways. This perspective is, then, not just bound to such highly complex and diverse cases as those in Luxembourg. Children in all countries commute between at least one ECEC service and the home (Brooker, 2006; Kousholt, 2011). Moreover, and if one looks closely enough, one finds very diverse, complex 
and unequal forms of ECEC arrangements even in unified systems, such as Germany's (e.g., Betz, 2013).

Secondly, this spatial thinking can also be very helpful for understanding the diversity of children's enactment of their multiple identities between ECEC, schools and families. This is because it expands the recent focus on the fixed boundaries between diverse 'cultural models' operating at these sites (e.g. Brooker, 2006; Heedegard, 2011) and lead to more relational ways of thinking which see those identities as situated through networks of people, things, places and ideas in flux. This kind of spatial thinking, therefore, lays pathways to prevent researchers from taking "certain kinds of fixity and boundedness for granted" and encourage them instead to "start with the fact of mobility" (Cresswell, 2011, p. 551). Hence, such a mobility perspective results also in other conceptions of ECEC systems, as it transforms the common view on borders and boundaries established through administrative and political processes into a view which 'sees' relations (Fenwick, 2012). Ultimately, this could also remind governments - including Luxembourg's one - to take into account, that a 'child-centred' reorganisation of ECEC systems should also include children's perspectives and the complex positionalities and spatialities which result in the everyday reproduction of those systems in children's enacted ECEC arrangements.

\section{Acknowledgements}

The CHILD-project was funded by Luxembourg's Fonds Nationale de la Recherche (FNR), (C12/SC/3991009, 2013-2016). I like to thank all the participants of the study and the two anonymous referees and especially Zsuzsa Millei for their helpful suggestions in developing this paper.

\section{References}

Ansell, N. (2009). Childhood and the politics of scale: Descaling children's geographies? Progress in Human Geography, 33(2), 190-209.

Bollig, S. (2015). The multiple geographies of early childhood education and care: An ethnographic approach to the places and spaces of young children's care arrangements. In S. Bollig, M.S. Honig, S. Neumann, \& C. Seele (Eds.), MultiPluriTrans in educational ethnography (pp. 99-118). Bielefeld und Columbia: Transcript.

Bollig, S., Honig, M.-S., \& Nienhaus, S. (2016). Vielfalt betreuter Kindheiten. Ethnographische Fallstudien zu den Bildungs- und Betreuungsarrangements junger Kinder. Luxembourg: Université du Luxembourg.

Bollig, S., \& Millei, Z. (2018). Spaces of early childhood. Introduction. Journal of Pedagogy, 9(1), 5-20. 
Brooker, L. (2006). From home to the home corner: Observing children's identitymaintenance in early childhood settings. Children \& Society, 20, 116-127.

Betz, T. (2013). Ungleichheit im Vorschulalter. Einrichtungsbezogene Bildungsund Betreuungsarrangements unter sozialwissenschaftlicher Perspektive. In M. Wolf, E. Dietrich-Daum, M. Heidegger, \& E. Fleischer (Eds.), Child Care. Kulturen, Konzepte und Politiken der Fremdbetreuung von Kindern (p. 117-131). Weinheim: Beltz Juventa.

Claessens, A., \& Chen, J. (2013). Multiple child care arrangement and child well being: Early care experiences in Australia. Early Childhood Research Quarterly, 28, 49-61.

Clark, A., Kjorholt, A.T., \& Moss, P. (2005). Beyond listening. Children's perspectives on early childhood services. Bristol, University Press.

Creswell, T. (2011). Mobilities I: Catching Up. Progress in Human Geography, 35 (4), 550-558.

Corsaro, W. (2018). The sociology of childhood (5th ed.). Thousand Oaks, CA: Sage.

De Groot, K. (2010). “There's Elly, It Must Be Tuesday": Discontinuity in child care programs and its impact on the development of peer relationships in young children. Early Childhood Education Journal, 38 (2), 153-164.

Fenwick, T. (2012). Reading educational reform with actor'network theory: Fluid spaces, otherings, and ambivalences. In T. Fenwick, \& R. Edwards (Eds.), Researching education through actor'network theory (pp. 97-116). Oxford: Blackwell-Wiley.

Gulløv, E. (2003). Creating a natural place for children: An ethnographic study of Danish kindergartens. In K. Fog Olwig, \& E. Gulløv (Eds.), Children`s places - cross-cultural perspectives (pp. 23-38). London, Routledge.

Heedegard, M. (2012). A cultural-historical approach to children's development of multiple cultural identities. In M. Kontopodis, C. Wulf, \& B. Fichtner (Eds.), Children, development and education (pp. 117-135). Dodrecht: Springer.

Hengst, H. (2018). Multiples Werden, lebenslanges Lernen. In T. Betz, S. Bollig, M. Joos, \& S. Neumann (Eds.): Institutionalisierungen von Kindheit (pp. 94-110). Weinheim: Beltz Juventa.

Honig, M.-S., \& Bock, T. (2017). Luxembourg - ECEC workforce profile. In I. Oberhuemer, \& I. Schreyer (Eds.), Workforce profiles in systems of early childhood education and care in Europe. www.seepro.eu/English/Country_Reports.html.

Karila, K., \& Alasuutari, M. (2012). Drawing partnership on paper: How do the forms for individual educational plans frame parent-teacher relationship? International Journal about Parents in Education, 6 (1), 14-26.

Kousholt, D. (2011). Researching family through the everyday lives of children across home and day care in Denmark. Ethos, 39(1), 98-114.

Markström, A., \& Halldén, G. (2009). Children's strategies for agency in preschool. Children and Society, 23(2), 112-122.

Massey, D. (2003). Space, place and gender. Minneapolis: University Press.

Massey, D. (2005). For space. London: SAGE.

Mohn, B., Bollig, S. (2016). Children navigating borders. Transition practices in day care routine. Double-DVD. Berlin: DorhmannVerlag.

OECD (2015). Starting strong IV: Monitoring quality in early childhood education and care. Paris: OECD Publishing. 
O'Connell, R. (2010). How is childminding family like? Family day care, food and the reproduction of identity at the public/private interface. The Sociological Review, 58(4), 563-586.

Qvortrup, J., Corsaro, W.A., \& Honig, M.-S. (Eds.). (2009). The palgrave handbook of childhood studies. Basingstoke: Palgrave.

Schatzki, T. R. (2002). The site of the social: A philosophical account of the constitution of social life and change. University Park: Pennsylvania State University Press.

Schatzki, T. R. (2011). Where the action is. On large social phenomena such as sociotechnical regimes. Working Paper 1 of the Sustainable Practices Research Group. http://www.sprg.ac.uk/uploads/schatzki-wp1.pdf (Accessed: 12.10.2013).

Seele, C. (2016). 'Doing education' between monolingual norms and multilingual realities: An ethnography of multilingualism in early childhood education and care. London: E \& E Publishers.

Sheppard, E. (2002). The spaces and times of globalization: Place, scale, networks, and positionality. Economic Geography, 78(3), 307-330.

Stratigos, T., Bradley, B., \& Sumsion, J. (2014). Infants, family day care and the politics of belonging. International Journal of Early Childhood, 46(2), 171-186.

Sylva, K., Stein, A. Leach, P., Barnes, J., Malmberg, L.E. and the FCCC-team (2006). Family and child factors related to the use of non-maternal infant care. Early Childhood Research Quarterly, 22(1), 118-136.

Vandenbroeck, M., De Visscher, S., Van Nuffel, K., \& Ferla, J. (2008). Mothers' search for infant child care: The dynamic relation between availability and desirability in a continental European welfare state. Early Childhood Research Quarterly, 23(2), 245-258.

\section{Author:}

Sabine Bollig, Ph.D.

University of Trier

Department of Education

Section Social Pedagogy

Trier

54286

Germany

E-mail: bolligs@uni-trier.de 